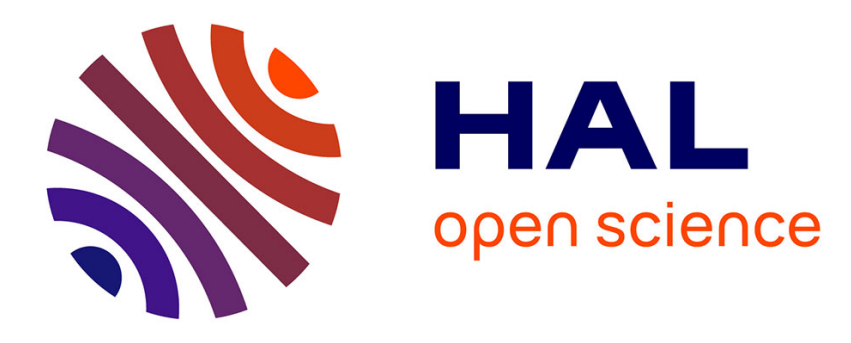

\title{
Knowledge Without Observation: Body Image or Body Schema?
}

Frédérique De Vignemont

\section{To cite this version:}

Frédérique De Vignemont. Knowledge Without Observation: Body Image or Body Schema?. Christoph Limbeck-Lilienau; Friedrich Stadler. The Philosophy of Perception, De Gruyter, pp.323334, 2019, 10.1515/9783110657920-018. ijn_03034544

\section{HAL Id: ijn_03034544 \\ https://hal.science/ijn_03034544}

Submitted on 1 Dec 2020

HAL is a multi-disciplinary open access archive for the deposit and dissemination of scientific research documents, whether they are published or not. The documents may come from teaching and research institutions in France or abroad, or from public or private research centers.
L'archive ouverte pluridisciplinaire HAL, est destinée au dépôt et à la diffusion de documents scientifiques de niveau recherche, publiés ou non, émanant des établissements d'enseignement et de recherche français ou étrangers, des laboratoires publics ou privés. 


\title{
Frédérique de Vignemont
}

\section{Knowledge Without Observation: Body Image or Body Schema?}

\begin{abstract}
Look up at the ceiling while your right arm is moved to the right. Attempt to recapture the original uninterpreted experience. Try to undo the lessons of time! Now somehow one cannot shake off the belief that the arm has gone to the right. Well, try again. Hard. Attempt to transfer all attention away from the limb and onto the feelings. Scrutinise them. Now tell us about them. Then you cannot in doing so help mentioning that they were in your arm, which was over to the right, poised like such and such, near to such and such a part of the body. (O’Shaughnessy, 1980, vol. 1, p. 157)
\end{abstract}

Please obey O'Shaughnessy, focus on your body and undo the lessons of time. What can you say about the posture of your limbs? And how do you know it? O'Shaughnessy defends the view that our bodily knowledge is based in what we feel, in the spatial phenomenology of our bodily sensations. However, Wittgenstein, and later Anscombe, note that the use of the term "feeling" is misleading. It is not because we talk of sensations of a specific property $X$ that we do have them. Instead, what we may really have is a kind of direct knowledge of $X$. The confusion arises because in some rare cases it seems to us that $X$ whereas $X$ is not true. Such errors do not show that we feel that $X$. On their view indeed, they only show that we are entitled to talk of knowledge when $X$ is true. The problem is then to decide when our knowledge is really based on feelings and when it is not. Here I will focus exclusively on the case of bodily knowledge, and more specifically on its spatial dimension. Not only do I know where the various parts of my body are, but I also know where I am touched and where I am in pain. The questions are: how do I have such knowledge? Do I feel it or do I directly know it? In this paper I will describe Wittgenstein and Anscombe's theory, according to which bodily sensations play no epistemic role. They famously claimed that the sense of position - the ability to report how the limbs are located - does not depend on sensations of position. In this sense, bodily knowledge differs from perceptual knowledge. I know that the sky is blue in virtue of having a visual experience of the blueness of the sky but I know that my legs are crossed independently of the sensation I may have of them being that way. Why is there such a difference? What reasons do Wittgenstein and Anscombe have to deny that bodily sensations play an epistemic role? They claim that the content that bodily sensations are endowed with cannot explain the beliefs that we form about our bodily posture. On their view, it is not fine-grained enough compared to the richness of our bodily knowledge. In addition, it separately describable from the beliefs 
themselves. I will argue that these objections do not suffice to show that bodily sensations play no epistemic role.

\section{The Poverty of Stimulus}

I let my index finger make an easy pendulum movement of small amplitude. I either hardly feel it, or don't feel it at all. Perhaps a little in the tip of the finger, as a slight tension. (Not at all in the joint.) And this sensation advised me of the movement? - for I can describe the movement exactly. "But after all, you must feel it, otherwise you wouldn't know (without looking) how your finger was moving". But "knowing" it only means: being able to describe it. (Wittgenstein, 1978)

According to Wittgenstein, the content of bodily sensations is too poor compared to the richness of bodily knowledge. Therefore, the former is insufficient to ground the latter. But is there really such a gap between what we feel and what we know? It is true that the phenomenology of bodily sensations is most of the time relatively limited, less detailed than the phenomenology of visual experiences, for instance, which can be analysed as full of fine-grained colour shades and well-individuated 3D shapes that move around. The crucial question is whether the relative poverty of our bodily sensations is a problem. One may indeed reply to Wittgenstein that bodily awareness is limited not only at the experiential level but also at the doxastic one. Although Wittgenstein pretends to be able to describe his finger movement exactly, it is not clear that it is the case. The knowledge that we have of our bodily movements is relatively sketchy. For instance, I doubt that Wittgenstein knows the amplitude of his finger movement. All he knows is that it is small. And there is a good reason why it is so roughgrained. There is indeed rarely any need to have fine-grained knowledge of our bodily position. Compare with vision. You need to know if this apple has a more reddish shade than this other apple in order to decide which one is ready to be eaten. There is no equivalent of this situation for bodily knowledge. When we need detailed and precise information about our body, it is only when we move it. Then indeed we cannot afford to have a sketchy representation of the position of our limbs because if it were the case the cost would be too high: we would simply fail to achieve our movements and reach our goal. What is important here is to clearly distinguish the declarative knowledge we have that supports the description we can make of our bodily position and the practical knowledge that we use to guide our bodily actions. Another way to put it is to draw a distinction between what is known in the literature as the body schema (sensorimotor repre- 
sentations that encode information necessary to guide action) and the body image (perceptual representations for recognition). The body schema must be finegrained but the body image does not have to be. When we act, we need to have precise and detailed information about the posture of our limbs. But it does not matter whether we have precise and detailed beliefs about it. In other words, it is sufficient to know that our legs are crossed; we do not need to know in which specific angle. Consequently, the fact that the content of bodily sensations is poor is not an argument against its role for declarative bodily knowledge. It rather seems that they coincide.

Wittgenstein, however, does not only argue that the content of bodily sensations is insufficient. He also argues that we have bodily knowledge in the absence of bodily sensations. He acknowledges that when we are anaesthetized we are able neither to feel sensations nor to describe the posture of our body. But he claims this does not show that we normally can report that our arm is bent because of the corresponding sensation. On his view, there are some circumstances in which we can be aware of the position of our body and yet have no bodily sensation. This is the case when we simply do not pay attention to our body. Hence, he concludes, bodily awareness does not depend on bodily sensations.

The fact is that most of the time we do not pay attention to our body (with the exception of learning and painful situations). For instance, while typing on a laptop, we do not precisely experience the posture our fingers on the keyboard. Our awareness is primarily occupied by the content of what we are typing, by the external world, rather than by the bodily medium that allows us to perceive it and to move through it. The question then is dual: can we then describe the position of our body and do we really have no bodily sensation? Again, I believe that Wittgenstein confuses our practical and our declarative knowledge. When you do not pay attention at all to your body, you still have information about its bodily posture that you process unconsciously and that you can use for changing position for instance, but this is not the same as to say that you can describe the position of your limbs. It is only when you are asked to focus on your body that you suddenly realize that your legs are crossed. Before that, you simply had no idea. Hence, even if we experienced no bodily sensations, that would not be a problem since we would also have no beliefs about our body. Furthermore, one may challenge the idea that we feel nothing without attention. This seems indeed to assume a very tight connection between attention and sensations, a connection that might not be warranted. Take the example of vision: it is generally assumed that we have visual experiences not only about what we focus on but also about what is in the periphery. Why would that be different for bodily experiences? 
We shall now turn to the problem that appears as the most fundamental for Wittgenstein and Anscombe, that is, the fact that the content of bodily sensations is not independent enough from the content of bodily knowledge.

\section{Independent Sensations}

... a man usually knows the position of his limbs without observation. It is without observation, because nothing shews him the position of his limbs; it is not as if he were going by a tingle in his knee, which is the sign that it is bent and not straight. Where we can speak of separately describable sensations, having which is in some sense our criterion for saying something, then we can speak of observing that thing. (Anscombe, 1957, p. 13)

According to Anscombe, bodily knowledge cannot be grounded in sensations because only sensations whose content is "independently describable" can play an epistemic role. For example, there is a sensation of going down in a lift since one can provide an independent description of its internal content in terms of lightness and of one's stomach lurching upward. By contrast, it is not legitimate to talk of sensation of sitting cross-legged, Anscombe claims, because there is no such independent description that can be given. Her argument can be summarized as follows:

(i) Only independent content can be used as the epistemic basis for judgments.

(ii) One cannot provide an independent description in the case of bodily position.

(III) Thus, bodily knowledge is knowledge without observation.

The interpretation of the notion of knowledge without observation has given rise to many debates and I shall not go into them here. I just want to highlight three main issues. The first concerns Anscombe's epistemological theory. Why do contents have to be independent to ground judgments? The second problem is that the whole argument rests on the assumption (ii), according to which one cannot provide an independent description in the case of bodily position: "no question of any appearance of the position to me, of any sensations which give me the position" (Anscombe, 1962, p. 58). But why is it so? Anscombe does not give any argument. She merely states that there cannot be independent descriptions. It then seems that the whole argument relies on phenomenological intuitions. But can one settle the debate by a direct use of our introspection in everyday life? As said earlier, most of the time bodily sensations are recessive and 
people have usually contradictory intuitions. This introspective quest is made even more difficult by the fact that we are not really sure of what we should look for. This is the third and most fundamental problem. The distinction between sensations whose content can be and sensations whose content cannot be separately describable is far from being clear and Anscombe's (1962, p. 57) own examples are not helpful. For instance, she claims that "the visual impression of a blue expanse" can ground the judgment that the sky is blue. Since she defends the view that sensations can be captured in intentional terms (Anscombe, 1965), her point is not that there is a qualitative raw feel of blueness independently of the visual property of blue. But then it is not clear in what sense this qualifies as an independent description and it may sometimes be difficult to see why perceptual awareness does not fall into the same category as bodily awareness. It may then be helpful to go back to her own definition:

\footnotetext{
When I say: 'the sensation (e.g. of giving a reflex kick) is not separable' I mean that the internal description of the ' sensation '-the description of the sensation-content-is the very same as the description of the fact known; when that is so, I should deny that we can speak of observing that fact by means of the alleged sensation. If we are considering an expression of the form 'sensation of X', we need to ask whether the words 'of X' are a description of the sensation content, or whether the sensation has some different content and $\mathrm{X}$ is what produces or always goes with it. (Anscombe, 1962, p. 56, my emphasis)
}

Here we can reconstruct two criteria for a sensation of $\mathrm{X}$ to be independent: (i) the content should not coincide with the content that is believed, and (ii) the content should be about what is systematically associated with X. However, I believe these two criteria to be unsatisfactory because they are too liberal.

Consider the positive criterion (" $\mathrm{X}$ is what produces or always goes with it"). Imagine the following hypothetical scenario. Whenever I believe my legs to be crossed, I experience the taste of chocolate in my mouth. On the basis of such gustatory experiences, I can infer that my legs are crossed. Shall we then conclude that the chocolate taste is the independent description of my feeling of having my legs crossed? Such a conclusion does not seem right, at least if we take seriously Anscombe's original epistemic starting point. On her view, sensations must be able to ground knowledge. But if we describe the internal content of the sensation of $X$ in terms of its side effects, then it can happen that the side effects occur for reasons other than X. It would be a logical fallacy to conclude that my legs are crossed on the only basis of their side effect. If now we describe the internal content of the sensation of $X$ in terms of its causes, then this is also problematic because other factors can prevent $X$ to be true. Consequently, it seems that mere causal connections, or even worse systematic association, cannot provide 
robust epistemic ground, and that they are not promising candidates for independent description. ${ }^{1}$

Let us now consider the negative criterion (not "the very same as the description of the fact known"). In response to this definition, Harcourt (2008) offers the following criterion for independent description: a sensation of bodily posture is independent if it can seem to one that one is in a specific bodily posture while one correctly judges that one is not. Anscombe's view can indeed accommodate the fact that one can be mistaken about one's bodily properties. However, what seems to be more problematic for her are cases in which the content of the alleged sensation is at odds not only with reality, but also with the content of the judgment. Harcourt then argues that there are bodily illusions, and concludes that bodily knowledge must thus be observational. The failure of Anscombe's argument would then simply come from the fact that she has overlooked the manifold of illusions that can happen even for bodily awareness. As Smith (2002, p. 24) noted:

It is tempting to think that because our bodies are, as it were, so close to us, the scope for illusions here is minimal. In fact, however, recent research in this area has presented some of the most striking illusions in all the literature.

A well-known example is called the Pinocchio illusion (Lackner, 1988). If the tendons of your arm muscles are vibrated at a certain frequency, you experience illusory arm movements. You feel, for instance, your arm moving away from you if your biceps tendon is vibrated. If you simultaneously grasp your nose, you experience your nose as elongating by as much as $30 \mathrm{~cm}$. The Pinocchio illusion constitutes the solution of a sensorimotor conflict between erroneous proprioceptive information (i.e. your arm moving away from you) and accurate tactile information (i.e. contact of your nose and your fingers). Interestingly, this illusion can occur although you are fully aware that this is not true. Hence, it can seem to one that one's arm is stretched while one correctly judges that it is not. Another famous example is the rubber hand illusion (Botvinick and Cohen, 1998). In the classic experimental set-up, one sits with one's arm hidden behind a screen, while fixating on a rubber hand presented in one's bodily alignment; the rubber hand can then be touched either in synchrony or in asynchrony with one's hand. After a couple of minutes, it has been repeatedly shown that there are significant

1 It is interesting to note that Bermúdez (2015), requires the content of sensations to be not only independent, but also "focused". Their content must provide information that is precise and specific because if they are too vague, they fail to justify the specific judgment that one makes. 
differences between synchronous and asynchronous conditions. Participants report that they feel tactile sensations as being located not on their real hand that is stroked, but on the rubber hand. Furthermore, they mislocalize the finger that was touched in the direction of the location of the finger of the rubber hand. On Harcourt's view, such bodily illusions show that the sensation of bodily position is separately describable and thus, that Anscombe is wrong: bodily knowledge is observational.

The situation, however, is more complex. Harcourt is right that there are many bodily illusions that remain insensitive to beliefs in the same way as visual illusions. Yet this does not suffice to show that bodily knowledge is observational. McDowell (2011) rightly points out that attitudes other than feelings and sensations can be encapsulated and immune to the influence of beliefs and judgments. Consequently, one can dispense with sensations and provide a cognitive interpretation of bodily illusions. To refute Harcourt's argument, however, does not show that Anscombe is right. Instead, the discussion between McDowell and Harcourt merely reveals that Anscombe's criterion is too vague. Even if the content is not the very same as the description of the fact known, this does not show that it is the content of a sensation.

What this brief discussion reveals is that Anscombe does not provide a clear definition of independent sensations, which can be easily operationalized. In the absence of such a definition, we cannot determine whether there are bodily sensations whose content is independent and that can ground bodily knowledge, or not. Even more problematic for her, if we take her to her words and use the criteria that she gives, it seems that there are such sensations.

\section{Knowledge Without Observation}

I now want to focus on the notion of bodily knowledge without observation, which may be more helpful than the notion of independent content. According to Anscombe, knowledge without observation should be understood in motor terms. In a nutshell, knowing that your legs are crossed is not feeling them to be crossed; it is knowing how to uncross them. Her view shares some similarities with the more recent enactivist approach, which gives a central role to the procedural knowledge of how the way in which one moves affects the sensory signals 
that one receives (Noë, 2004; O'Regan, 2011). ${ }^{2}$ Because of these similarities, however, she also shares the same difficulties (for more details on enactivism, see Vignemont, 2011). Consider the following report given by a neurological patient:

But, I don't understand that. You put something there; I do not feel anything and yet I got there with my finger. How does that happen? (Paillard et al., 1983, p. 550)

This patient, who was blindfolded, was amazed at her own ability to point to the site at which she was touched on her hand while she felt absolutely no sensation of having been touched. She suffered from what is called 'numbsense' in the neuropsychological literature (also called 'blind touch'). Following cortical or subcortical lesions, patients with numbsense become completely anaesthetized on their right side. Yet despite their apparent numbness, they are able to guide their opposite hand towards the approximate site at which they are touched when so instructed, and to their own surprise. Likewise, although they do not feel their arm location, they can accurately reach the position of their arm.

It may then seem that what Witggenstein and Anscombe describe (knowing without feeling) can actually happen. One might indeed say that these patients have bodily knowledge without observation. But do they really have knowledge? The patients are not able to form beliefs about the tactile stimuli and their arm position, even in a forced choice condition (Rossetti et al., 1995). They cannot describe that they were touched nor where they were. What is preserved is only their bodily know-how, their practical knowledge of how to reach for their arm. Interestingly, they are no better in judging the location of their sensation when they are acting at the same time; instead they become equally bad in the verbal and in the motor tasks (Rossetti et al., 1995). Numerous findings actually show dissociation between body schema and body image, between how we act and what we know (Vignemont, 2010). Another example concerns the rubber hand illusion. We saw earlier that participants mislocalize the location of their hand. If the motor interpretation of the notion of knowledge without observation were right, one could explain the effect as follows: participants localize their hand closer to the location of the rubber hand because they are misleadingly induced to expect that if they reach the location close to the rubber hand, they will touch their own hand. However, this explanation cannot account for the following facts. When asked, participants accurately direct their opposite hand to the real location of

2 There are, however, two main differences. First, enactivists do not make a distinction between vision and touch or proprioception, while Anscombe does. On her view, visual knowledge is observational. Secondly, enactivists aim to account for bodily experiences while Anscombe is not interested in bodily experiences and instead aims to account for bodily knowledge. 
their own hand that was touched, and not to the illusory location that they report (Kammers et al., 2009). Their reaching movements are not sensitive to the spatial illusion. Interestingly, when participants are asked a second time to make a perceptual judgement about the location of their touched hand after having moved, they are still sensitive to the illusion, and they still localize their hand as being closer to the location of the rubber hand than it was (although less so). Hence, what they describe about their body cannot be explained by their bodily knowhow.

What these findings show is that Anscombe's notion of knowledge without observation can be used to understand the body schema, that is, the bodily knowhow that guides us in ene's movements. Clearly, action guidance and control, which constantly require information about the body, are not mediated by bodily sensations. If we were to wait for us to be aware of our bodily position before making any motor adjustment, our movements would be slow and inefficient. Hence, to use Anscombe's phrase, the motor system "usually knows the position of his limbs without observation". But this is not true of the himself. What he describes is not based on his practical knowledge without observation. In other words, the body image cannot be reduced to the body schema.

\section{Conclusion}

In this paper I did not show that bodily sensations ground bodily knowledge. Instead I merely argued that there is no good reason to prevent them for doing so. There is a further motivation to argue that they play an epistemic role. If indeed they played none, as suggested by Anscombe and Wittgenstein, then bodily sensations seem to have no role whatsoever. One may then be tempted by an eliminativist conception, according to which bodily sensations are merely "philosophical fictions": they do not exist (Bermúdez, 2015). As far as I know, this is not what Anscombe or Wittgenstein wants to claim. But if indeed they reject such a conclusion, then they might simply grant that bodily sensations do play a role.

\section{References}

Anscombe, G. E. M. (1957). Intention. Ithaca: Cornell University Press.

Anscombe, G. E. M. (1962). On sensations of position. Analysis, 22(3), 55-8. 
Anscombe, G. E. M. (1965). The intentionality of sensation: A grammatical feature. In Ronald J. Butler (ed.), Analytic Philosophy. Blackwell. pp. 158-80.

Bermúdez, J. L. (2015). Bodily ownership, bodily awareness, and knowledge without observation. Analysis. 75 (1): 37-45.

Botvinick, M. and Cohen, J. (1998). Rubber hands 'feel' touch that eyes see. Nature, 391, 756.

Harcourt, E. (2008). Wittgenstein and Bodily Self-Knowledge. Philosophy and Phenomenological Research, 77:2, 299-333.

Kammers, M. P., de Vignemont, F., Verhagen, L., and Dijkerman, H. C. (2009a). The rubber hand illusion in action. Neuropsychologia, 47, 204-11.

Lackner, J. R. (1988), Some proprioceptive influences on the perceptual representation of body shape and orientation. Brain, 111, 281-97.

McDowell, J. (2011). Anscombe on bodily self-knowledge. Essays on Anscombe's Intention, edited by A. Ford, J. Hornsby, and F. Stoutland. Cambridge (MA): MIT Press.

Noë, A. (2004). Action in perception. Cambridge (MA): MIT Press.

O’Regan, K. (2011). Why red doesn't sound like a bell. Oxford: Oxford University Press.

O'Shaughnessy, B. (1980). The will. Vol. 1. Cambridge: Cambridge University Press.

Paillard, J., Michel, F., and Stelmach, G. (1983). Localization without content. A tactile analogue of "blind sight". Archives of Neurology, 40, 548-51.

Rossetti, Y., Rode, G., and Boisson, D. (1995). Implicit processing of somaesthetic information: a dissociation between where and how? Neuroreport. 6, 506-10.

Smith, A. D. (2002). The problem of perception. Cambridge (MA): Harvard University Press.

de Vignemont, F. (2010), Body schema and body image: pros and cons. Neuropsychologia, 48(3), 669-80.

de Vignemont, F. (2011), A mosquito bite against the enactive view to bodily experiences. Journal of Philosophy, CVIII, 4, 188-204.

Wittgenstein, L. (1978). Philosophical Investigations. Tr. G.E.M. Anscombe. Oxford: Blackwell. 